\title{
Equity Education: a longitudinal study comparing multicultural knowledge and dispositions of field-based and campus-based teacher candidates
}

\author{
Johnnie Thompson, Linda Bakken \& Wei-Cheng Mau
}

\begin{abstract}
Two groups of teacher candidates, enrolled either in a field-based or campus-based program, were measured before and after their first semester of teacher education courses and again at the end of their student teaching semester. The two groups were compared regarding their knowledge of multicultural education issues, dispositions towards diverse populations, and their perception of confidence in teaching in diverse classrooms. Multivariate analyses of variance (MANOVAs) with repeated measures indicated that there was a significant increase for both groups in multicultural knowledge after the first semester and that this knowledge was maintained throughout their program. Results also indicated that there was a significant increase in a positive attitude toward multicultural education for both groups after their first semester; however, this positive attitude was not maintained. In terms of perceived confidence in teaching, both groups increased after the first semester, and the field-based group continued to increase until the end of their undergraduate program. The findings suggest that the field-based experience continues to impact students' multicultural knowledge and their perceived self-efficacy.
\end{abstract}

\section{Introduction}

Inequality in educational outcomes for all students has been an issue since the inception of the American educational system. The values, commitments, and professional ethics that influence behaviors toward students, families, and communities affect student learning (Weiner \& Cohen, 2003). Initiating positive change requires four key factors: exposure to different cultures, information, first-hand experiences, and guided reflection (Garmon, 2004). Early exposure to real-life situations and the ability to observe skilled practitioners often has a positive impact on students. When school site personnel and university faculty collaborate to create an effective learning environment, results are often positive. The need is great for those who initially train teachers to collaborate with those who hire and supervise teachers. Collaboration is key. Essential to collaboration is a need to determine the most effective model.

The increasing ethnic diversity of American schools demands that educators possess the ability to communicate and interact effectively with those who are different from themselves. Educators must develop attitudes, skills, and understandings which initiate positive outcomes. According to the National Education Association (2003), 90\% of all teachers are European American and two-thirds are females. The US Department of Education (1994) states that the percentage of students of color has steadily increased such that they now comprise $30 \%$ of the total school population. Further, the US Census Bureau (1998) indicates that among children and adolescents enrolled in schools in 2000,65.1\% were white, $15.5 \%$ African American, 13.2\% Latino, and 4.6\% Asian American. These data also project that the minority population will outnumber the white majority by 2050 . This disparity of ethnicity between teachers and pupils is unlikely to change (Bennett, 1999).

Even with the past efforts of desegregation, the most common type of student body is racially homogenous. Lewis indicated that

A study of enrollment patterns in Illinois public schools reported that $70 \%$ of African American children attended schools that were at least $75 \%$ minority students. Sixty percent of Latino students attended schools that were at least $75 \%$ minority. Only $8 \%$ of 
African American and $18 \%$ of Latino children attended school in districts that were less than $25 \%$ minority. (Lewis, 1995, p. 14)

Nationally, about one-third of African American and Latino students attend schools that are $90 \%$ to $100 \%$ minority (Orfield \& Yun, 1999). Sleeter \& Grant (2007) add that white students, also, are most likely to attend schools that are predominantly European American in population. Because of the diversity within our student population, teachers must be prepared to positively interact with all students. In most cases, the life experiences (influenced by ethnicity, gender, and economic status) of teachers and students vary greatly from each other; and, according to Bennett (1999), life experiences are a primary influence on an individual's perceptions, ideals, and world views.

The vast majority of college students (white middle class) who enter teacher education programs are ill-prepared to teach children with backgrounds different from their own; and these students have little knowledge about, and experience with, different ethnic groups (Zimpher \& Ashburn, 1992). In classroom interactions, differences in sociocultural factors between teachers and students often become impenetrable obstacles to effective teaching and learning. When selecting learning examples and illustrations, teachers tend to draw from their own personal experiences and cultural frames of reference. These are more often irrelevant to culturally different students (Rodriguez, 1993). Change efforts must take into account the life experiences of the students. Institutions charged with the responsibility of preparing teachers have a moral and ethical responsibility to prepare teachers to be culturally responsive; that is, they need 'to enable teachers to respond to the educational needs of their diverse student populations by planning and developing culturally rich curricula and by using instructional methodologies that are based upon knowledge of how culture influences cognitive styles' (Smith, 1998, p. 9).

The traditional teacher education training programs provide limited opportunities to broaden life experiences that extend beyond awareness to application and interaction with school-aged children. These traditional programs require less than a quarter of teacher candidate training to take place in actual classroom teaching or apprenticeship situations (National Center for Research on Teacher Education, 1991). Although the guidelines of the National Council for Accreditation of Teacher Education (2002) encourage the preparation of teachers who demonstrate the ability to effectively address students from diverse backgrounds, often programs do not integrate multicultural education in thorough, persistent, and overt ways for adult learners (Jung, 1993).

Information alone does not necessarily alter or change attitudes or actions. In order to maximize effectiveness, knowledge and contact in a friendly and supportive environment is necessary to accelerate the process of gaining tolerance and reducing negative attitudes (Allport, 1958). Successful endeavors depend greatly upon timely application of theories, types of environments, appropriateness of methodology, and pre- and post-dispositions of candidates. In order to overcome the rigidity that often characterizes candidates' perspectives on issues concerning teaching and diversity, scholars have acknowledged the need for extended field experiences early in teacher education programs (for example, Birrell, 1994). Holt-Reynolds (1992) has pointed out that field experiences enable teachers to link university coursework with classroom instruction in ways that increase the utility of knowledge with classroom instruction gained during pre-service programs. The early, extended field-based experience, peer tutoring, mentorship, collaboration, and on-site classes should be designed to reinforce theory with practice.

In a previous study, Thompson et al (1998) conducted a cross-sectional study comparing fieldbased pre-service teachers with campus-based pre-service teachers in the areas of multicultural knowledge, attitudes toward multicultural issues, and perceived confidence in teaching in a diverse setting. Results indicated that significant changes occurred for both groups (field-based and campusbased) after their first semester in the teacher education program in which both groups were enrolled in a multicultural education class (but no between-group differences). For those students who were 
preparing for their student teaching semester (at the end of the teacher preparation program), there were significant differences between the two groups in their knowledge of multicultural education, suggesting that the field-based students maintained their level of multicultural knowledge, whereas the campusbased students did not. Although differences in disposition toward diversity issues and confidence in teaching in an ethnically diverse classroom were not significant, the trends were in the same direction.

Therefore, in the present study we decided to follow the same candidates in the two programs from their first experiences through their final student teaching semester. We examined these two different foci of training teacher candidates. One program was campus-based and concentrated on theory with limited field experiences; the second program was field-based with an extended field experience component and limited theory. Both groups followed the same sequence of courses.

We asked the following questions: Among teacher candidates:

1. in the area of multicultural knowledge:

a. would there be a long-term effect on multicultural knowledge based on prolonged and early field experiences?

b. would the group with prolonged and early field experiences have more multicultural knowledge than a group with limited field experiences?

2. in the area of dispositions toward issues of diversity:

a. would there be a long-term effect on attitudes based on prolonged and early field experiences?

b. would the group with prolonged and early field experiences have a greater change in their attitudes than the group with limited field experiences?

3. in the area of perceived teacher efficacy:

a. would there be a long-term effect on perceived teacher efficacy based on prolonged and early field experiences?

b. would the group with prolonged and early field experiences perceive themselves to have greater teacher efficacy than the group with limited field experiences?

\section{Methods}

The field-based cohort consisted of 22 candidates and there were 43 candidates in the campusbased cohort. There were 55 females and 10 males comprising both experimental and control groups; over $90 \%$ of the candidates were European American. A total of 11 field-based candidates and 24 campusbased candidates completed all follow-up surveys.

Knowledge of multicultural education issues was measured by a modification of the Survey on Multicultural Education, Part B (Sparks \& Wayman, 1990). This section of the survey has a 10-item forcedresponse scale (for example, 'Do you understand the diverse perspectives of various ethnic groups and their contributions to society?') that requires a 'yes', 'no', or 'not sure' answer from the participant. Statements were scored as follows: no $=0$; not sure $=0$; yes $=1$. Scoring could range from 0 to 10 points. Attitudes toward multicultural education were measured by a modification of Part $\mathrm{C}$ of the same survey. This section consists of 19 items on a 5-point Likert-type scale (for example, 'To what degree do you believe in providing an understanding of the customs and traditions of diverse cultural backgrounds?'). These items were scored from a -2 for 'strongly disagree' to a +2 for 'strongly agree'. Scores could range from -38 to +38 . The survey is straightforward in the content of the questions; therefore, only face validity has been established for the instrument. Reliability coefficients estimated for this sample were 0.63 for Part B (multicultural knowledge) and 0.93 for Part C (multicultural attitudes).

In order to measure perceived confidence in teaching, participants were measured on the Revised Teacher Efficacy Scale (Gibson \& Dembo, 1984). The survey consists of 20 items on a 6-point Likert-type scale that ranged from a 1 'strongly agree' to 6 'strongly disagree' (for example, 'When a student does better than usual, many times it is because I exerted a little extra effort.'). Scores could range from 20 to 120. Internal consistency using Cronbach's alpha yielded a reliability of 0.74 . The Teacher Efficacy Scale 
has been developed and modified over a period of years. Gibson \& Dembo report that as a result of their work, the scale reports convergent validity significant beyond the 0.05 level, support for discriminant validity, and beginning evidence of construct validity. The authors also indicate internal consistency of 0.79 for the scale (for a more complete discussion of the validity and reliability of the instrument, see Gibson \& Dembo [1984]).

The teacher training program is a block-structured experience, in which candidates take prescribed courses over a period of four semesters. It begins with foundation courses which present issues of diversity (Core 1) and culminates in a semester of student teaching (Core 4). For the campus-based candidates, each semester provides limited field experiences. For the field-based group, classes are held on the site of their field assignment, and they spend considerably more time in the school classroom for the four semesters of their teacher training program.

The survey questionnaires were given at the beginning of the Fall semester (in which the candidates began their teacher training, or Core 1) to both groups in the cohort and again at the end of that semester. The two groups were assessed for the final time at the end of the final semester of their teacher training (Core 4).

\section{Field-Based Group}

The field-based group was those candidates assigned to a public school site. This group was immersed in early and extensive field experiences, concurrent with coursework in educational theory and methodology. The block structure remained; however, considerably more time is spent with application in the school classroom. For the first two cores, candidates spend 15 hours per week on site: 4-5 hours in on-site content coursework and 15-16 hours in the elementary or middle school classrooms. For Core 3, candidates spend 10 hours per week on site ( 3 hours in content coursework and 7 hours in the classroom). Core 4 candidates spend 35 hours per week on site ( 1 hour of this is in the university classroom), working in the classroom and performing other professional responsibilities. Field-based candidates were assigned to work with an experienced certified classroom teacher (clinical faculty associate [CFA]). The CFAs involved the candidates in grade-level planning, applications of theory, and classroom experiences. Classroom experiences included tutoring, small-group instruction, instructional design, and action research. These candidates were expected to become participating members of the on-site team; they built long-term relationships with staff, students, parents, and community members.

\section{Campus-Based Group}

The campus-based group had limited exposure in the public schools until their student teaching semester. They followed the course of study for the block program, which included field experiences in the schools. The block program is a result of a carefully reviewed and systematically revised program that organizes the content into four sequential blocks of coursework. Weekly field experiences integrate courses within each block with application to the profession. The first set of professional courses (Core 1) provides a firm footing in the understanding of human diversity. It blocks together three perspectives of diversity - culture, development, and ability - in one semester with a one-hour field experience which integrates knowledge from all three. The second set of professional courses (Core 2) focuses on general issues of curriculum, instruction, and evaluation, and also includes a one-hour field experience. The third set of professional courses (Core 3 ) focuses on content-specific curriculum and methods with a two-credithour pre-student teaching field experience. The fourth and final block of professional courses (Core 4) consists primarily of student teaching. Each block provides a field experience, in which the candidates spend a portion of their time observing students in the classroom and implementing the strategies and techniques that they learn in their courses. During Cores 1 and 2, they spend one hour a week in their field experience, in Core 3 they spend two hours a week in the field, and it is not until Core 4 that they spend an extended time in the classroom. 


\section{Results}

Multivariate analyses of variance (MANOVAs) with repeated measures were used to examine the within-subject (time; pretest versus posttest versus follow-up) and between-subject (site; field versus campus) differences. Results of the MANOVAs indicated a significant within-subject difference $(F[6,28]=$ $13.43, p<.000)$. There were no significant between-subject differences $(F[3,31]=0.74, p<.54)$, nor was there an interaction effect $(F[6,28]=1.61, p<.18)$. Consequently, univariate tests indicated a significant within-subject difference in multicultural knowledge $(F[2,33]=20.89, p<.000)$, multicultural attitudes $(F[2,33]=6.83, p<.002)$, and teaching efficacy $(F[2,33]=6.51, p<.003)$. Tests of within-subject contrasts also indicated a quadratic Time*Site interaction $(F[1,33]=4.24, p<.047)$.

Post hoc follow-up analyses showed that, regardless of site, significant differences were found between the follow-up test $(M=9.28)$ and pretest $(M=7.13)$ in multicultural knowledge, between the posttest $(M=32.86)$ and follow-up test $(M=26.90)$ in multicultural attitudes, and between the follow-up test $(M=85.07)$ and pretest $(M=79.00)$ in teaching efficacy. The results of the post hoc analyses also indicated a significant difference in teaching efficacy between the posttest $(M=86.08)$ and follow-up test $(M=79.25)$ for campus-based students only.

\section{Discussion}

There were several potentially important findings from the current study. First, in the areas of multicultural knowledge (a disposition towards diversity), there was a significant change in both the fieldbased candidates and the campus-based candidates after their first semester in the teacher preparation program. However, there were no significant differences found between the two groups. In other words, it appears that both approaches were effective in impacting multicultural competencies. Second, there was also a significant change in candidates' perceived efficacy in teaching after their first semester in teacher education, regardless of the approach. This suggests that both methods were effective in increasing perceived teacher efficacy. Third, the data indicated that in the area of multicultural knowledge, candidates in both groups retained the gains made during their first semester to the end of the undergraduate program. However, candidates in both groups decreased in their attitudes toward multicultural issues to a level lower than the attitudes they held at the beginning of their program. Results of this study indicate that, unless a guided, specialized, and sequential multicultural curriculum component is included each semester, the positive attitudes gained by early and extended exposure to diverse populations will not be maintained. And fourth, the data suggest that the field-based candidates continued to increase in their perceptions of teacher efficacy throughout their undergraduate program, whereas the campus-based candidates increased from the beginning to the end of their first semester, but did not continue to increase in their perceptions of teaching effectiveness after that time. This extends the findings from the cross-sectional data (Thompson et al, 1998) and notes the long-term impact of the field-based program on candidate perception of teacher efficacy.

Tentative conclusions that can be drawn from this research suggest that field-based programs may not be conducive to changing candidates' knowledge and dispositions toward multicultural issues any more than a campus-based program; the value of field-based programs may come in contributing to candidates' growing confidence in their capabilities to teach in a pluralistic environment.

\section{Limitations}

There are several limitations inherent in this study. First, the number of candidates is not large and, in fact, getting measures for the three data-collecting times resulted in considerable attrition. The results would have been more significant if all the candidates who started and completed the undergraduate teaching program had participated fully in the study. Second, the field-based program assumes that those public school teachers who serve as cooperating teachers for the students are truly master teachers. It could very well be possible that the teachers themselves did not provide the kind of 
modeling necessary for long-term change in candidates' dispositions toward students who were different from themselves.

Although these findings point out the need for much more research in determining the relevance of field-based programs, the current study suggests that field-based programs have an impact on candidates' multicultural knowledge. Of even greater importance, field-based programs may be a viable vehicle for building candidates' confidence in teaching in diverse classrooms. They may provide teacher education programs with the link needed in preparing teachers to teach a diverse population of students.

No single course or program of study can fill the knowledge and experiential gaps that nonminority candidates have as they prepare to teach. Issues of diversity need to be reviewed, reinforced, and taught throughout the teacher education program in order to impact a more lasting change in candidates' ways of thinking. As Allport (1958, p. 451) so eloquently put it: 'Information seldom sticks unless mixed with attitudinal glue'.

\section{References}

Allport, G.W. (1958) The Nature of Prejudice. New York: Doubleday Anchor Books.

Bennett, C.I. (1999) Comprehensive Multicultural Education: theory and practice, 3rd edn. Needham Heights: Allyn \& Bacon.

Birrell, J.R. (1994) The Influence of Prior Experience on Beginning Preservice Education Teachers. Paper presented at American Education Research Association, New Orleans, April 2-6.

Garmon, M.A. (2004) Changing Preservice Teachers' Attitudes/Beliefs about Diversity: what are the critical factors? Journal of Teacher Education, 55, 201-213. http://dx.doi.org/10.1177/0022487104263080

Gibson, S. \& Dembo, M.H. (1984) Teacher Efficacy: a construct validation, Journal of Educational Psychology, 76, 569-582. http://dx.doi.org/10.1037/0022-0663.76.4.569

Holt-Reynolds, D. (1992) Personal History-Based Beliefs Are Relevant Prior Knowledge in Course Work, American Educational Journal, 29, 325-349.

Jung, B. (1993) Curriculum Development: teacher empowering and professional, in M.J. O'Hair \& S.J. Odell (Eds) Diversity and Teaching: teacher education yearbook, 285-299. Fort Worth: Harcourt Brace.

Lewis, J.H. (1995) Preserving Privilege: inequity of the Illinois educational finance system. Chicago: Chicago Urban League.

National Center for Research on Teacher Education (1991) Findings from the Teacher Education and Learning to Teach Strategy. East Lansing: College of Education, Michigan State University.

National Council for Accreditation of Teacher Education (2002) NCATE. http//www:ncate.org (home website); information can be obtain by contacting organization. National Council for the Accreditation of Teacher Education (NCATE).

National Education Association (NEA) (2003) Status of the American Public School Teacher. Washington, DC: NEA.

Orfield, G. \& Yun, J.T. (1999) Resegregation in American Schools. Cambridge, MA: Civil Rights Project, Harvard University.

Rodriguez, H.R. (1993) Every Child Can Learn, Momentum, 24(2), 51-52.

Sleeter, C.E. \& Grant, C.A. (2007) Making Choices for Multicultural Education: five approaches to race, class, and gender, 5th ed. Hoboken: Wiley.

Smith, G.P. (1998) Common Sense about Uncommon Knowledge: the knowledge bases for diversity. Washington, DC: AACTE Publications.

Sparks, W. \& Wayman, L. (1990) Multicultural Understanding in Physical Education. Ypsilanti: College of Education, Eastern Michigan University. ERIC Document Reproduction Service, ED 318584. 
Thompson, J., Bakken, L. \& Mau, W.C. (1998) Comparing Interactions of Field-Based and Campus-Based Preservice Teachers, Teaching Education,10, 67-75.

US Census Bureau (1998) Current Population Survey. School Enrollment: social and economic characteristics of students. Washington, DC: US Department of Commerce.

US Department of Education (1994) Mini-Digest of Education Statistics. Washington, DC: National Center for Education Statistics, US Department of Education.

Weiner, H. \& Cohen, A.R. (2003) Dispositions in Teacher Education Programs: an opportunity for reform. Paper presented at 2nd Annual National Conference on Teacher Dispositions, Eastern Kentucky University, 19 November.

http://www.education.eku.edu/dispositions/resources/Dispositions\%20Proceedings\%20Session \%20K. doc

Zimpher, N. \& Ashburn, E. (1992) Countering Parochialism among Teacher Candidates, in D. Wilworth (Ed.) Diversity in Teacher Education, 40-62. San Francisco: Jossey-Bass. 